\title{
Corrigendum: Inhibitory Control Impairment on Somatosensory Gating Due to Aging: An Event-Related Potential Study
}

\author{
Juan L. Terrasa, Pedro Montoya, Ana M. González-Roldán* and Carolina Sitges \\ Cognitive and Affective Neuroscience and Clinical Psychology, Research Institute of Health Sciences (IUNICS), Balearic \\ Islands Health Research Institute, University of the Balearic Islands, Palma, Spain
}

Keywords: aging, somatosensory gating, paired-pulse task, event-related potential, source localization, inhibitory deficit hypothesis

OPEN ACCESS

Approved by:

Frontiers In Human Neuroscience

Editorial Office,

Frontiers Media SA, Switzerland

*Correspondence:

Ana M. González-Roldán

anamaria.gonzalez@uib.es

Received: 31 July 2018 Accepted: 01 August 2018 Published: 21 August 2018

Citation:

Terrasa JL, Montoya P González-Roldán AM and Sitges $C$ (2018) Corrigendum: Inhibitory Control Impairment on Somatosensory Gating Due to Aging: An Event-Related Potential Study.

Front. Hum. Neurosci. 12:333. doi: 10.3389/fnhum.2018.00333

\section{A Corrigendum on:}

Inhibitory Control Impairment on Somatosensory Gating Due to Aging: An Event-Related Potential Study

by Terrasa, J. L., Montoya, P., González-Roldán, A. M., and Sitges, C. (2018). Front. Hum. Neurosci. 12:280. doi: 10.3389/fnhum.2018.00280

There is an error in the Funding statement. The correct number for PSI2016-78637-P is PSI201678637-P AEI/FEDER, UE. In addition, the correct number for PSI2015-66295-R is PSI2015-66295$\mathrm{R}$ AEI/FEDER, UE. The authors apologize for this error and state that this does not change the scientific conclusions of the article in any way.

The original article has been updated.

Conflict of Interest Statement: The authors declare that the research was conducted in the absence of any commercial or financial relationships that could be construed as a potential conflict of interest.

Copyright () 2018 Terrasa, Montoya, González-Roldán and Sitges. This is an open-access article distributed under the terms of the Creative Commons Attribution License (CC BY). The use, distribution or reproduction in other forums is permitted, provided the original author(s) and the copyright owner(s) are credited and that the original publication in this journal is cited, in accordance with accepted academic practice. No use, distribution or reproduction is permitted which does not comply with these terms. 